\title{
Simultaneous Determination of Montelukast Sodium S-Enantiomer and A5 Enantiomers in Montelukast Sodium Bulk Drug by Normal-Phase Chiral HPLC
}

\author{
D. WANG*, C. ZHOU, R. CONG, Y. LI AND X. WANG \\ National Recognized Enterprise Technology Center of Disha Pharmaceutical Group, No. 55 Qilu Road, Economic and \\ Technological Development Zone, Weihai-264200, China
}

Wang, et al.: Simultaneous Determination of Montelukast Enantiomers by Normal-Phase Chiral HPLC

A sensitive and validated high performance liquid chromatographic method was developed for determination of montelukast sodium S-enantiomer, A5 and A5 R-enantiomer in montelukast sodium bulk drug. Chromatographic analysis was performed on a Daicel Chiralpak ${ }^{\circledR}$ AD-H column at $30^{\circ}$, the flow rate was set $0.9 \mathrm{ml} / \mathrm{min}$, eluent was n-hexane:isopropanol:ethanol:trifluoroacetic acid:diethylamine (65:15:20:0.1:0.1, $v / v / v / v / v)$, determination wavelength was $280 \mathrm{~nm}$ and the injection volume was $10 \mu \mathrm{l}$. The high performance liquid chromatography was validated for system suitability, precision, limit of detection and limit of quantitation, linearity, accuracy and robustness. The results indicated that the system suitability test met the requirement with resolution more than 2.0 between montelukast sodium enantiomers and greater than 6.0 between A5 enantiomers. The values of relative standard deviation were not more than $4.0 \%$ for precision test, the limit of detection from 0.11 to $0.24 \mu \mathrm{g} / \mathrm{ml}$, and the limit of quantitation from $0.22 \mathrm{to} 0.61 \mu \mathrm{g} / \mathrm{ml}$, respectively. The linearity correlation coefficients $(r)$ were greater than 0.99 for three analytes. The recovery values were ranged from 89.35 to $108.78 \%$. The proposed method was adequate for the determination of montelukast sodium S-enantiomer, A5 and A5 R-enantiomer in montelukast sodium bulk drug.

Key words: Montelukast sodium, montelukast sodium S-enantiomer, normal-phase chiral HPLC, A5 R-enantiomer

Leukotrienes, derived from the biological metabolism of arachidonic acid, refers to a group of inflammatory mediators ${ }^{[1,2]}$, which could be able to cause a series of inflammations reaction by bonding with leukotriene receptor $^{[3,4]}$. Recently, following the position confirmed and the understanding of functional mechanism of leukotriene receptor in bronchial hyper responsiveness ${ }^{[5,6]}$, the treatment for asthma with leukotriene receptor antagonist has been a new tendency. Montelukast sodium, Singulair, [1-[[[(1R)1-[3-[(E)-2-(7-chloroquinolin-2-yl)-ethenyl]phenyl]3-[2-(1-hydroxy- 1-methylethyl)phenyl]-propyl] sulfanyl]methyl]cyclopropyl]acetate, developed by Merck Frosst Canada in the 1990s and used as one of the selective antagonists of leukotriene receptor. It could decrease inflammatory reactions mediated by leukotrienes, lower blood pressure ${ }^{[7-9]}$, and also used to treat asthma ${ }^{[10,11]}$, allergic rhinitis ${ }^{[12]}$ and heart attack ${ }^{[13]}$. Currently, montelukast sodium is a widely prescribed for the treatment of asthma and symptoms of allergies, because of its prominent efficacy and less adverse reaction $^{[14,15]}$.

Owing to a chiral centre at the methane carbon of the thioether side chain, montelukast sodium has an enantiomer, i.e. montelukast sodium S-enantiomer (fig. 1). It is reported that S- and R-enantiomers of a chiral drug usually have different biological activities, one could be selected as a drug with a therapeutic action while the other to be avoided due to toxic or side effects ${ }^{[16,17]}$. As a LTD4 (leukotriene D4) receptor antagonist, montelukast sodium has a superior in vitro and in vivo compared with its $\mathrm{S}$-enantiomer ${ }^{[7]}$. Based on International Conference of Harmonization (ICH) Q7 guiding principle, the S-enantiomer content

This is an open access article distributed under the terms of the Creative Commons Attribution-NonCommercial-ShareAlike 3.0 License, which allows others to remix, tweak, and build upon the work non-commercially, as long as the author is credited and the new creations are licensed under the identical terms 
in montelukast sodium bulk drug should be strictly controlled $^{[18]}$. In montelukast sodium quality criterion embodied in European Pharmacopeia 8.0 (EP 8.0), the specified limit of S-enantiomer was not more than $0.2 \%$. A5 as one critical material for synthesizing montelukast sodium ${ }^{[19,20]}$ (fig. 1), also possesses a chiral centre and has a enantiomer, i.e., A5 R-enantiomer. Both A5 and A5 R-enantiomer are process impurities, which are likely introduced into end product, therefore, A5 and A5 R-enantiomer also should be monitored for ensuring the quality of montelukast sodium.

Although a few analytical methods for determination of montelukast sodium S-enantiomer have been reported, for instance, Redondo et al. ${ }^{[21]}$ developed a test method with an enantioselective proton nuclear magnetic resonance ( ${ }^{1} \mathrm{H}$ NMR) spectroscopy by adding (-)-cinchonidine into montelukast sodium, but because of a low sensitivity, it was not used for quantitation of S-enantiomer at very low levels (below $0.5 \%$ ), and the method established by Lida et al. ${ }^{[22]}$ and the method embodied in EP 8.0 all performed on an AGP chiral column with stationary phase of $\alpha$-acid glycoprotein ${ }^{[23]}$, it is easily destroyed under various severe conditions, such as organic reagent, acidic or alkaline etc. Hence, its life time is too short conventionally. In addition, the capacity factor of chiral-AGP column is smaller. However, in EP 8.0, the injection concentration was $1000 \mu \mathrm{g} / \mathrm{ml}$, which is more than the maximum concentration of $100 \mu \mathrm{g} / \mathrm{ml}$, undoubtedly, it may seriously destroy the column. Radhakrishnan et $a .^{[24]}$ developed a chiral high performance liquid chromatography (HPLC) method for determination of montelukast S-enantiomer in montelukast

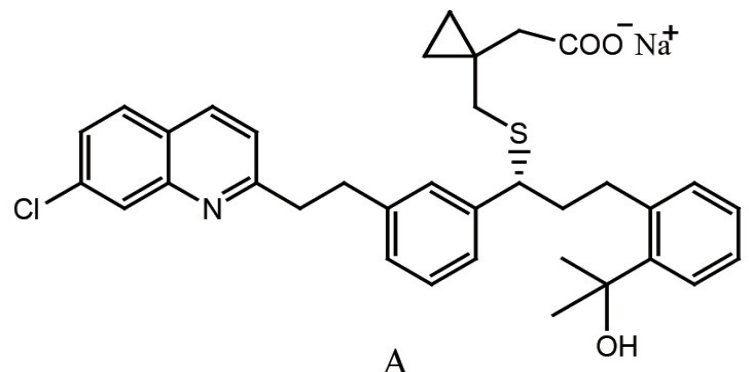

A

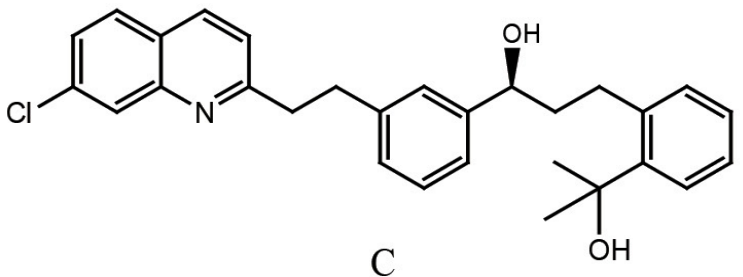

sodium on a chiral pak-IA column with an eluent of n-hexane:ethanol:1,4-dioxane:trifluoroacetic acid (TFA):diethylamine (DEA) (65:25:10:0.3:0.05, v/v/ $\mathrm{v} / \mathrm{v} / \mathrm{v})$, but its sensitivity was poor with the limit of quantitation (LOQ) of $200 \mathrm{ng}$, it accounted for $2 \%$ of quality of montelukast sodium sample $(1000 \mu \mathrm{g} / \mathrm{ml}$ of montelukast sodium and $10 \mu \mathrm{l}$ injection volume), which does not meet the requirement of montelukast sodium quality criteria in EP 8.0. In addition, as process impurities, the contents of both A5 and A5 R-enantiomer should be strictly limited, however, up to now, there is not a method to be reported for determination of $\mathrm{A} 5$ and its enantiomer.

Given all this, the present study aimed to develop and validate a sensitive and robust method for simultaneous determination of montelukast sodium S-enantiomer, A5 and A5 R-enantiomer in montelukast sodium drug substance, and finally to meet the requirements for quality control of montelukast sodium bulk drug during industry production.

\section{MATERIALS AND METHODS}

All reagents were of HPLC grade unless specified. $\mathrm{N}$-hexane, ethanol and isopropanol were purchased from Tianjin Biaoshiqi Science and Technology Development Co. Ltd (Tianjin, China). DEA was of analytical grade obtained from Tianjin Dengke Chemical Reagent Co. Ltd (Tianjin, China). TFA was purchased from Aladdin Industrial Corporation (Shanghai, China).

Three lots of montelukast sodium samples were supplied by Institute of Pharmaceutical Research of
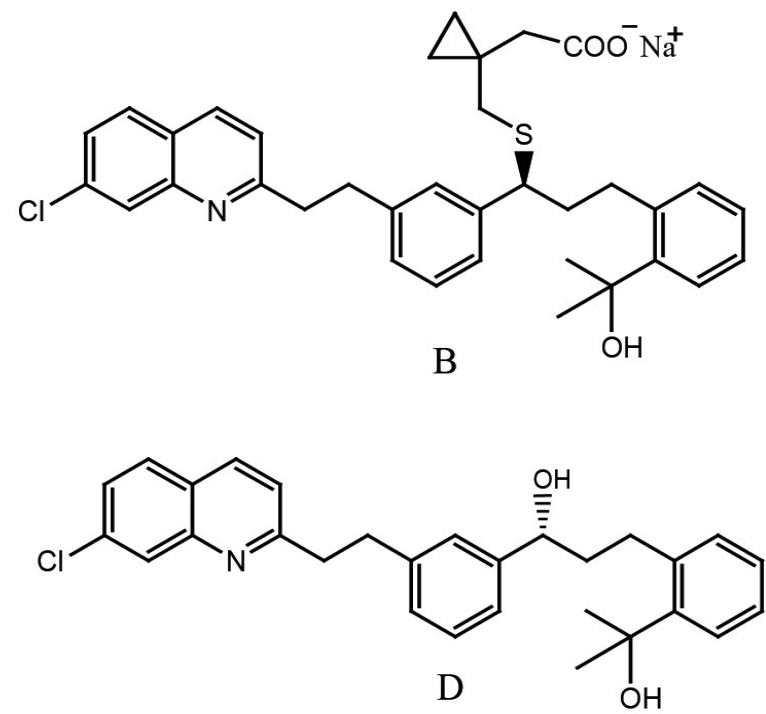

Fig. 1: The chemical structures of compounds

A. Montelukast sodium; B. S-enantiomer; C. A5 enantiomer and D. A5 R-enantiomer 
Disha Pharmaceutical Group. Montelukast sodium S-enantiomer was purchased from Molcan Corporation (Richmond Hill, Ontario, Canada) and montelukast sodium was obtained from National Institutes for Food and Drug Control (Beijing, China). A5 was purchased from Nenter and Co., Inc. (Jingzhou, Hubei, China) and A5 R-enantiomer was purchased from Toronto Research Chemicals (Toronto, Ontario, Canada).

\section{Liquid chromatography system:}

The chromatographic studies were performed on a Hitachi L-2000 liquid chromatography system (Hitachi Limited Corporation, Tokyo, Janpan) consists of L-2130 pump, L-2200 auto sampler, L-2420 UV/ Vis detector, AT-350 column oven (Tianjin Automatic Science Instrument Corporation Limited, Tianjin, China) and D-2000 Elite chromatographic work station used for monitoring and processing output signal. Hitachi U-2910 UV/Vis spectrophotometer (Hitachi Limited Corporation, Tokyo, Japan) was used for ultraviolet spectrum scan. The chiral columns used for development method were Chiralcel ${ }^{\circledR} \mathrm{OJ}-\mathrm{H}$ (cellulose tris (4-methylphenyl formiate) coated on silica-gel) $(250 \times 4.6 \mathrm{~mm}, 5 \mu \mathrm{m})$, Chiralpak ${ }^{\circledR}$ AD-H (amylose tris (3,5-dimethylphenyl carbamate) coated on silica-gel) $(250 \times 4.6 \mathrm{~mm}, 5 \mu \mathrm{m})$ from Daicel Chiral Technologies (China) Co., Ltd. (Shanghai, China) and OD52546 chiral column (cellulose tris (3,5-dimethylphenyl carbamate) coated on silica-gel) $(250 \times 4.6 \mathrm{~mm}, 5$ $\mu \mathrm{m}$ ) and SCDP52546 (single $\beta$-cyclodextrin coated on silica-gel) $(250 \times 4.6 \mathrm{~mm}, 5 \mu \mathrm{m})$ from Guangzhou Research and Creativity Biotechnology Co. Ltd (Guangzhou, China).

\section{Chromatographic conditions:}

The proposed method was carried out on a Chiralpak $^{\circledR} \quad$ AD-H chiral column $(250 \times 4.6$ $\mathrm{mm}, 5 \mu \mathrm{m}$ ) and the mobile phase consisted of n-hexane:isopropanol:ethanol:TFA:DEA $(65: 15: 20: 0.1: 0.1, \mathrm{v} / \mathrm{v} / \mathrm{v} / \mathrm{v} / \mathrm{v})$; the column oven was set $30^{\circ}$; the determine wavelength was set $280 \mathrm{~nm}$; the flow rate was $0.9 \mathrm{ml} / \mathrm{min}$ in isocratic elution and the injection volume was $10 \mu \mathrm{l}$.

\section{Sample preparation:}

System suitability solution was prepared by dissolving appropriate amount of montelukast sodium sample in $\mathrm{n}$-hexane:isopropanol:ethanol $(65: 15: 20, \mathrm{v} / \mathrm{v} / \mathrm{v})$, and adding right amount of standard store solution of montelukast sodium S-enantiomer $(50 \mu \mathrm{g} / \mathrm{ml})$, A5 $(300 \mu \mathrm{g} / \mathrm{ml})$ and A5 R-enantiomer $(100 \mu \mathrm{g} / \mathrm{ml})$ to give a final concentration of $1000 \mu \mathrm{g} / \mathrm{ml}$ for montelukast sodium sample and $10 \mu \mathrm{g} / \mathrm{ml}$ for montelukast sodium S-enantiomer, $10 \mu \mathrm{g} / \mathrm{ml}$ for A5 and $10 \mu \mathrm{g} / \mathrm{ml}$ for A5 $\mathrm{R}$-enantiomer, respectively. Test sample solution was made by dissolving a suitable amount of montelukast sodium sample in n-hexane:isopropanol:ethanol $(65: 15: 20, \mathrm{v} / \mathrm{v} / \mathrm{v})$, which concentration was $1000 \mu \mathrm{g} / \mathrm{ml}$.

\section{Method development:}

The UV spectrum scan from 190 to $420 \mathrm{~nm}$ was carried out on Hitachi U-2910 UV/Vis spectrophotometer for wavelength selection. The concentration of A5 was $10 \mu \mathrm{g} / \mathrm{ml}$, so that of montelukast sodium. The solvent was n-hexane:isopropanol:ethanol:TFA:DEA $(65: 15: 20: 0.1: 0.1, \mathrm{v} / \mathrm{v} / \mathrm{v} / \mathrm{v} / \mathrm{v})$. For selecting column, Chiralcel ${ }^{\circledR} \mathrm{OJ}-\mathrm{H}, \quad$ Chiralpak $^{\circledR} \mathrm{AD}-\mathrm{H}, \quad$ OD52546 and SCDP52546 chiral columns were chosen to separate montelukast sodium enantiomers and A5 enantiomers by injecting system suitability solution with the mobile phase of n-hexane:isopropanol:ethanol:TFA:DEA $(65: 15: 20: 0.1: 0.1, \mathrm{v} / \mathrm{v} / \mathrm{v} / \mathrm{v} / \mathrm{v})$ at $0.9 \mathrm{ml} / \mathrm{min}$, individually.

Various solvents including n-hexane, isopropanol, ethanol and different additives, such as TFA and DEA, were used in different combinations to get good peak resolutions and lesser run time. Different flow rates from 0.8 to $1.0 \mathrm{ml} / \mathrm{min}$ in isocratic mode have been studied to achieve a good peak separation. The column temperature was set at $25^{\circ}, 30^{\circ}$ and $35^{\circ}$ for optimizing according to its effects on peak resolutions and retention times of two pairs of enantiomers, respectively.

\section{Method Validation:}

The system suitability test was carried out to validate that whether montelukast sodium enantiomers and A5 enantiomers could be separated using the proposed method by injecting system suitability solution. The repeatability was checked by measuring the peak areas of montelukast sodium S-enantiomer, A5 and A5 R-enantiomer of successive injections of 6 individual system suitability solutions, the values of relative standard deviation (RSD) of 6 measure results were calculated for repeatability evaluation.

The intermediate precision was tested through measuring the peak areas of montelukast $\mathrm{S}$-enantiomers, A5 and A5 R-enantiomer of successive injections of 6 individual system suitability solutions by different analyst on different dates, the values of RSD of 6 measuring results were computed to evaluate the intermediate precision evaluation.

The limit of detection (LOD) and LOQ for montelukast 
sodium S-enantiomer, A5 and A5 R-enantiomer were estimated as the amounts for which that the signalto-noise ratios were $3: 1$ and $10: 1$, respectively, by injecting a series of diluent solutions of standard store solution of 3 analytes.

By quantitatively diluting the standard store solutions of montelukast sodium S-eantiomer, A5 and A5 R-enantiomer, a series of different concentration solutions ranging from the LOQ to $200 \%$ of the permitted maximum level (not more than $0.1 \%$ in test sample of $1000 \mu \mathrm{g} / \mathrm{ml}$ ), i.e. LOQ, $0.08 \%, 0.1 \%, 0.12 \%$, $0.15 \%$ and $0.2 \%$ for montelukast sodium S-enantiomer, A5 and A5 R-enantiomer were prepared in triplicate to evaluate linearity, respectively. Peak areas and concentrations of the analytes were subjected to regression analysis to calculate the calibration equation and the correlation coefficient (r).

Accuracy was evaluated by determination of recoveries of montelukast sodium S-enantiomer, A5 and A5 R-enantiomer at four levels, respectively. Considering the linear interval of the validated method, the tests were performed at the concentrations of spiked LOQ, 80,100 and $200 \%$ of limit level to montelukast sodium sample solution $(1000 \mu \mathrm{g} / \mathrm{ml})$, in six replicates, respectively. The recoveries were calculated using the Eqn. 1, recovery $(\%)=M_{\text {measured }} / M_{\text {spiked }} \times 100$, where, $\mathrm{M}_{\text {measured }}$ was the weight of spiked compound measured using the developed method, $M_{\text {spiked }}$ was the weight spiked into sample solution.

Method robustness was tested by modifying flow rate from 0.8 to $1.0 \mathrm{ml} / \mathrm{min}$, column temperature from 28 to $32^{\circ}$, additives content from $0.09 \%$ to $0.1 \%$ and employing columns from different lots. While a factor was investigating, the other chromatographic conditions were held constant. The chromatographic resolution between montelukast sodium and it's S-enantiomer; between A5 and its R-enantiomer were used to evaluate the method robustness.

The stability test of montelukast sodium test sample solution was studied by determination of test sample solution at $0,1,2,4,8,12 \mathrm{~h}$. The RSD of montelukast peak area was used to evaluate solution stability.

\section{RESULTS AND DISCUSSION}

The UV spectrum scan result showed that both A5 and montelukast sodium had a larger UV absorbance at $280 \mathrm{~nm}$ (fig. 2). Because of montelukast sodium quality criteria including in EP8.0 and some papers relative to determination of S-enantiomer all selected $280 \mathrm{~nm}$ as test wavelength, taking these reasons into consideration, the UV wavelength of $280 \mathrm{~nm}$ was selected as test wavelength.

Using the method, Chiralcel ${ }^{\circledR} \mathrm{OJ}-\mathrm{H}$, Chiralpak ${ }^{\circledR}$ ADH, OD52546 and SCDP52546 chiral columns were used to separate A5 and A5 R-enantiomer, montelukast sodium and its S-enantiomer. The results displayed that Daicel Chiracel ${ }^{\circledR}$ OJ-H chiral column could be employed for separation of A5 and A5 R-enantiomer, between them the resolution was more than 5.0, but the chromatographic peaks of montelukast sodium and its S-enantiomer were overlapped entirely (fig. 3a). Both OD52546 and SCDP52546 chiral columns also were not used to separate the two pairs of enantiomers. Using Daicel Chiralpak ${ }^{\circledR}$ AD-H chiral column, all the two pairs of optical isomers reached baseline separation with the resolution between montelukast sodium enantiomers more than 2.0 and between A5 enantiomers greater than 6.0 (fig. $3 b, c$ and d). The reason may be that each type of chiral column packing has a specific selectivity for separation of enantiomers with different chemical
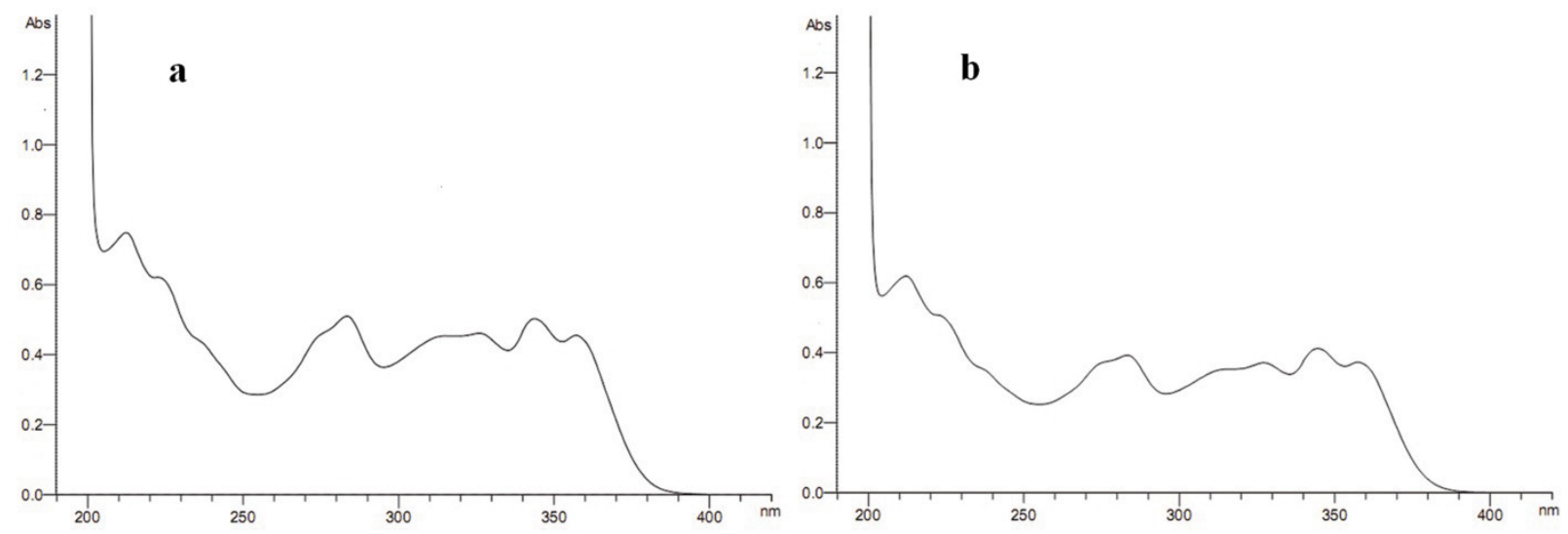

Fig. 2: UV spectrum from 190 to $420 \mathrm{~nm}$ a. A5 and b. montelukast sodium 

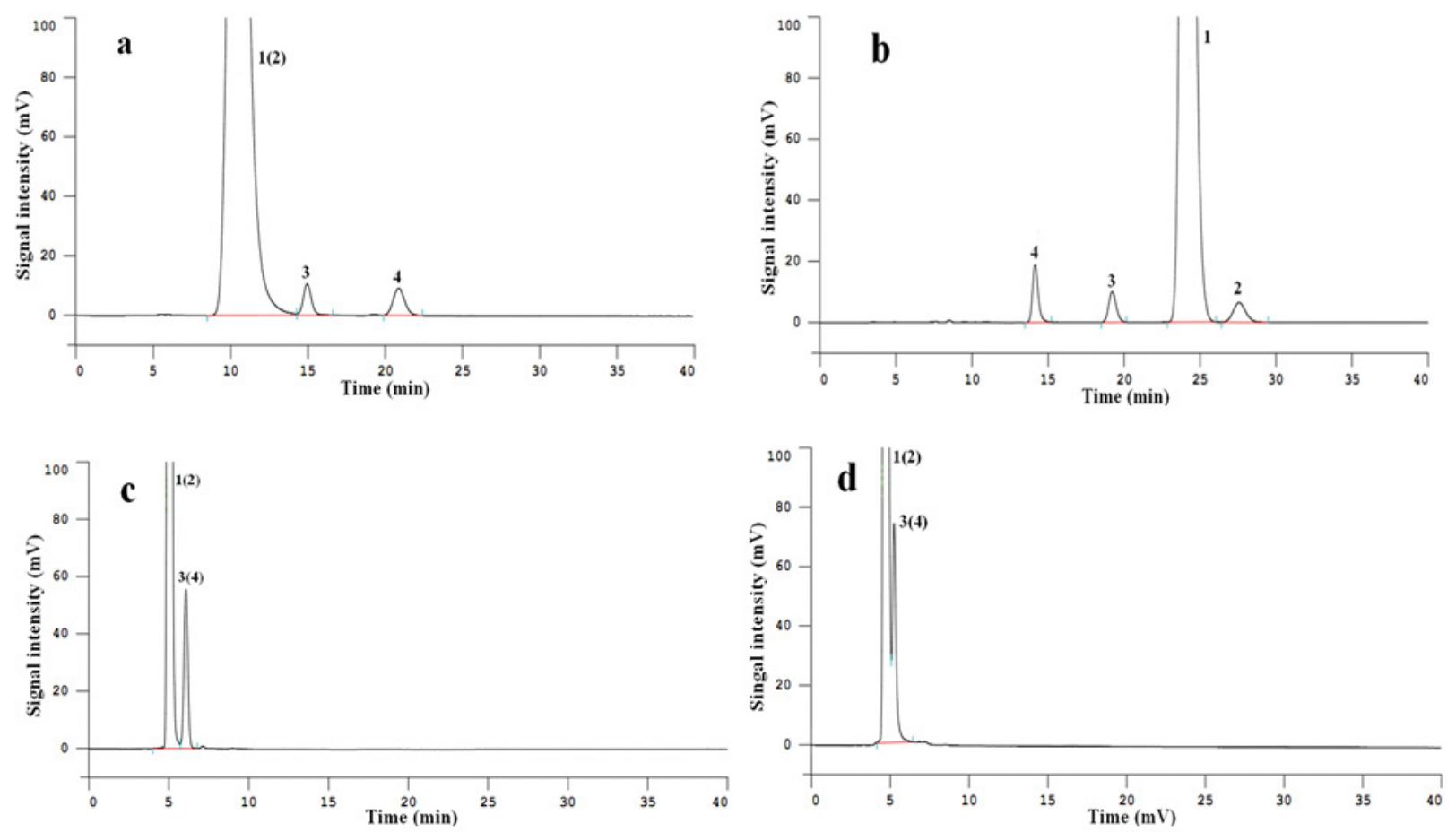

Fig. 3: Chromatograms of four compounds with different columns 1. Montelukast sodium; 2. S-enantiomer; 3. A5 enantiomer; 4. A5 R-enantiomer. a. Daicel Chiracel ${ }^{\circledR}$ OJ-H column; b. Daicel Chiralpak ${ }^{\circledR}$ AD-H column; c. OD52546 column and d. SCDP52546 column

structure. The stationary phase of Daicel Chirlpak ${ }^{\circledR}$ AD-H chiral column has a better ability to separate montelukast sodium enantiomers and A5 enantiomers, it could form diastereoisomer with montelukast sodium and its S-enantiomer, respectively and separate them, so was A5 and its R-enantiomer. Therefore, the Daicel Chiralpak ${ }^{\circledR}$ AD-H chiral column was chosen as separation column in this study.

N-hexane-ethanol-1,4-dioxane-TFA-DEA system was taken as eluent for separation of montelukast sodium enantiomers, that has been reported by Radhakrishnan et al. ${ }^{[24]}$ but, in view of the property of eluent, only the chiral column with bonded stationary phase can be used, that has restricted the use of that with coated stationary phase in determination of montelukast enantiomers. For the reason mentioned above, in this paper, n-hexane, ethanol and isopropanol were screened as candidates for composition of mobile phase, and because of alkalinity of montelukast sodium, a proper amount of DEA or TFA could be added for improvement of stereoselectivity.

In this section, the component ratio of mobile phase was expressed in terms of the ration of volume unless specified otherwise. The n-hexane selected as an elementary solvent of mobile phase, 5 kinds of eluent system of (a) n-hexane-isopropanol-ethanol-DEA-
TFA, (b) n-hexane-isopropanol-ethanol-DEA, (c) n-hexane-isopropanol-ethanol-TFA, (d) n-hexaneethanol-DEA-TFA, (e) n-hexane-isopropanol-DEATFA were screened for separation of montelukast sodium enantiomers and A5 enantiomers using proposed HPLC by injecting system suitability solution, respectively. The test results were shown in fig. 4.

The results displayed that both montelukast sodium enantiomers and A5 enantiomers can be well separated with resolution of 2.6 for montelukast sodium enantiomers and 6.7 for A5 R-enantiomers using (a) system while it was n-hexane:isopropanol:ethanol:DEA:TFA (65:15:20:0.1:0.1) (fig. 4a). Under the condition of (d) system, while the mobile phase was n-hexane-ethanolDEA-TFA (80:20:0.1:0.1), the chromatographic peak of A5 almost overlapped with that of montelukast sodium S-enantiomer. Under the condition of (e) system, when the mobile phase was n-hexane-isopropanol-DEATFA (80:20:0.1:0.1), both the montelukast sodium enantiomers and the A5 enantiomers achieved the baseline separation with each other, but the run time was too long with the time more than $40 \mathrm{~min}$. Performed on (c) system, while the eluent was n-hexane-isopropanolethanol-TFA (65:15:20:0.1), two pairs of enantiomers also obtained baseline separation, but the run time was 

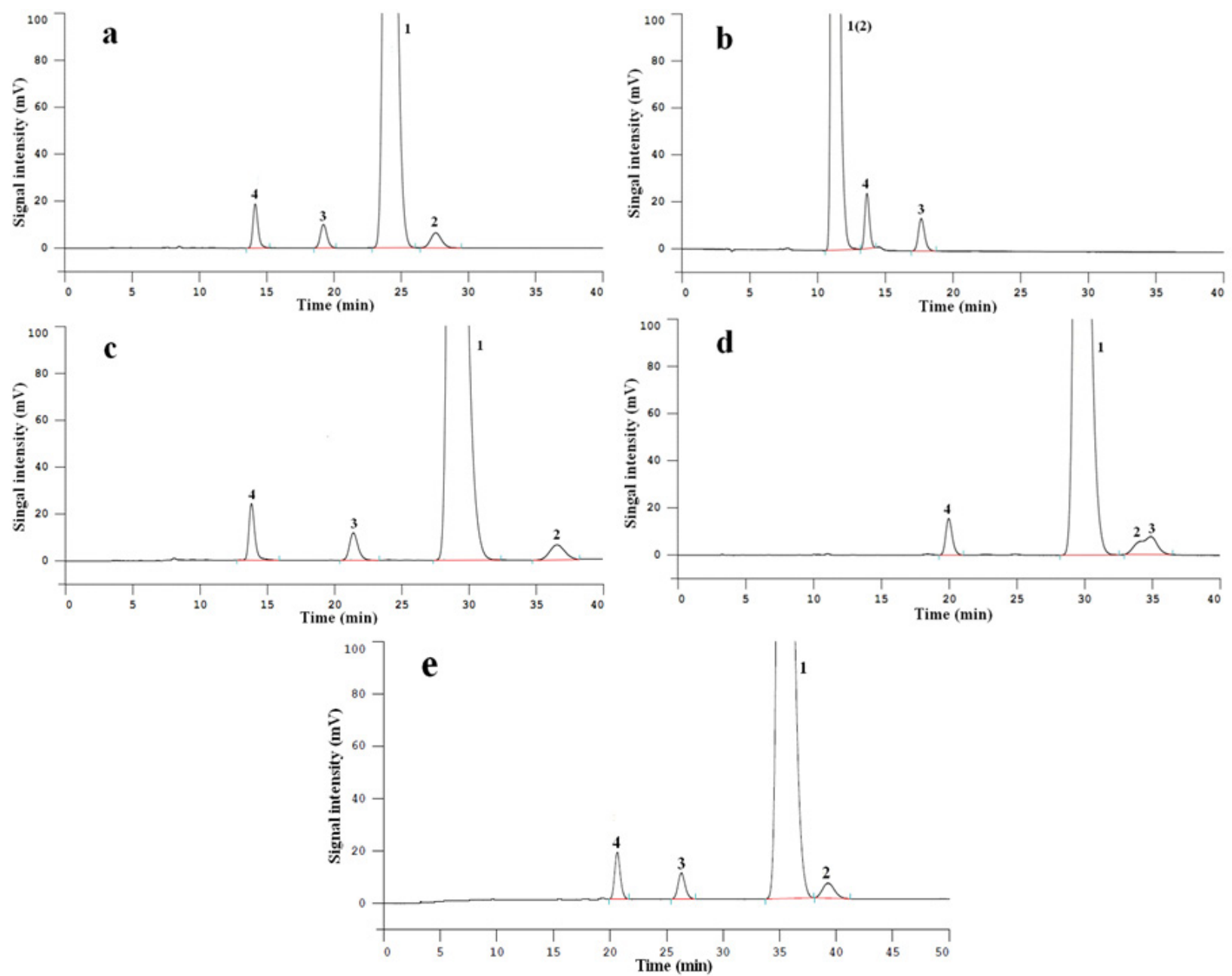

Fig. 4: Chromatograms of four compounds with different mobile phase system on Daicel Chiralpak ${ }^{\circledR}$ AD-H column 1. Montelukast sodium; 2. S-enantiomer; 3. A5 enantiomer and 4. A5 R-enantiomer. a. n-hexane:isopropanol:ethanol:DEA:TFA (65:15:20:0.1:0.1); b. n-hexane:isopropanol:ethanol:DEA (65:15:20:0.1); c. n-hexane:isopropanol:ethanol:TFA (65:15:20:0.1); d. n-hexane:ethanol:DEA:TFA (80:20:0.1:0.1) and e. n-hexane:isopropanol:DEA:TFA (80:20:0.1:0.1)

also too long and the values of peak spreading were too large compared with that under condition (a). On (b) system, while it was n-hexane-isopropanol-ethanolDEA (65:15:20:0.1), A5 enantiomers were well separated with the resolution of 5.5, but montelukast enantiomers were overlapped completely (fig. 4b, c, d and e).

In conclusion, the experimental results show that selecting n-hexane served as primary solvent, isopropanol is an important factor to facilitate separation of A5 with montelukast sodium S-enantiomer, and TFA is a critical factor for achieving separation of montelukast sodium and it's S-enantiomer. Furthermore, both ethanol and DEA play an important role in decreasing peak spreading, shortening run time and improving column efficiency. Through optimization of eluent composition, the optimal mobile phase system is n-hexane:isopropanol:ethanol:DEA:TFA system, and the best ratio was 65:15:20:0.1:0.1.
The 3 kinds of flow rates of $0.8,0.9$ and $1.0 \mathrm{ml} / \mathrm{min}$ were chosen for optimization of using the proposed method. The results showed the retention time of both montelukast sodium enantiomers and A5 enantiomers all moved toward gradually with the flow rate being faster, and the sample test period was shortened, but the column pressure was increased rapidly. Due to having no significant effect on the separations of 2 pairs of enantiomers, and taking column protection and analytical period into consideration, the flow rate of 0.9 $\mathrm{ml} / \mathrm{min}$ was selected in this study.

The column temperature was set at $25^{\circ}, 30^{\circ}$ and $35^{\circ}$ to studied the effect on separations of 2 pairs of enantiomers by injecting system suitability solution using the development method, respectively. The experiment results displayed that the retention times of all analytes were reduced following column temperature rising, but while column temperature was 

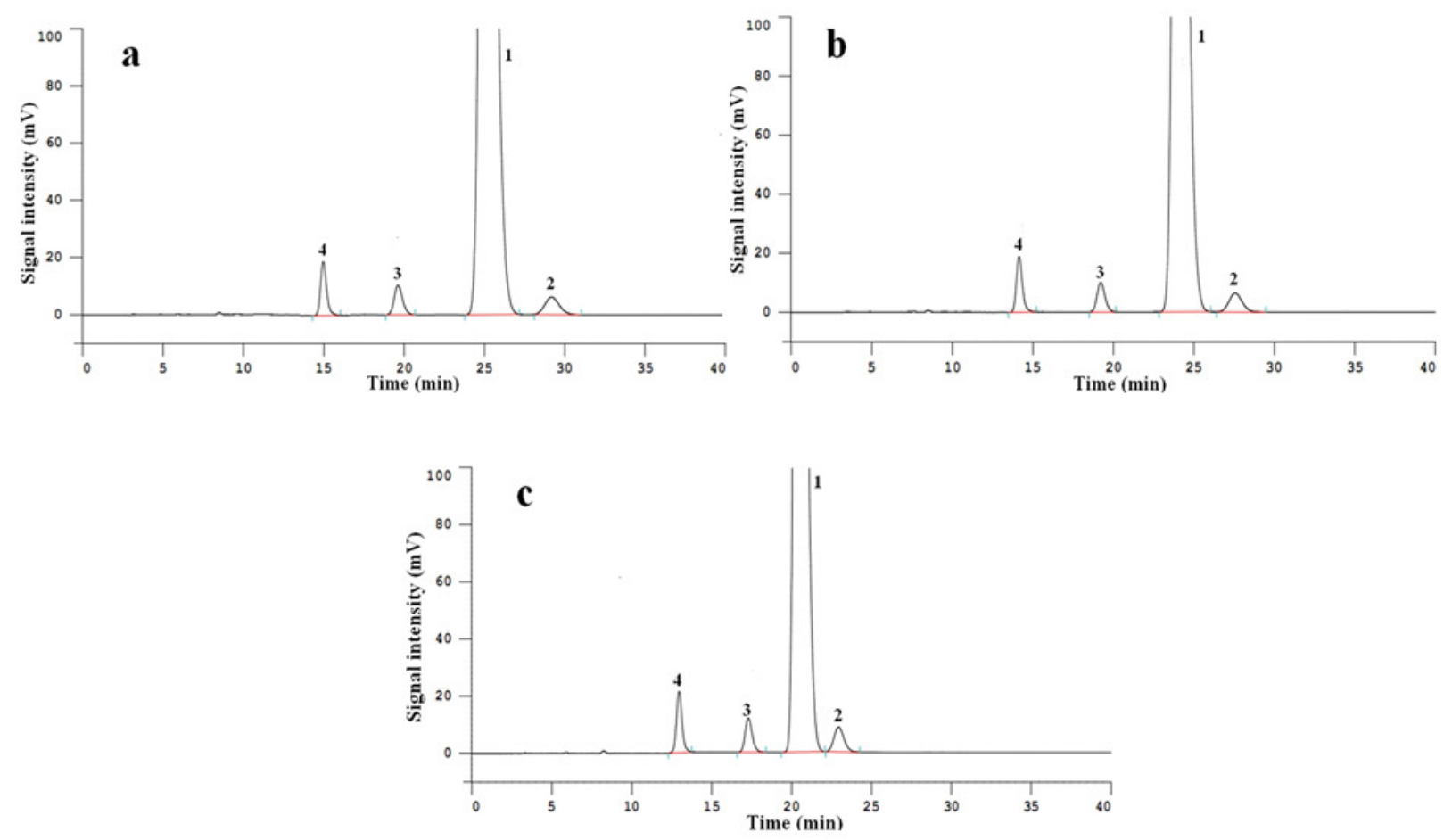

Fig. 5: Chromatograms of four compounds with different column temperature

1. montelukast sodium; 2. S-enantiomer; 3. A5 enantiomer and 4. A5 R-enantiomer; a. $25^{\circ}$; b. $30^{\circ}$ and c. $35^{\circ}$

$35^{\circ}$, the value of resolution between montelukast sodium enantiomers was 2.2 , it was smaller than that of $25^{\circ}$ and $30^{\circ}$. Furthermore, under the condition of $35^{\circ}$, running for long time can shortened service life of chiral column. Under the conditions of $25^{\circ}$ and $30^{\circ}$, both 2 pairs of enantiomers reached baseline separation with the resolution more than 2.4 , but the test time under the condition of $25^{\circ}$ was slightly longer compared with that of $30^{\circ}$ (fig. 5a, b and c), therefore, taking all factors into consideration, the column temperature was set at $30^{\circ}$.

The system suitability test results showed that both montelukast sodium enantiomers and A5 enantiomers were reached baseline separation, therefore, the method met the requirement of system suitability test (fig. $3 b$ ). The test results for repeatability showed that the RSDs of 6 measure results were 3.2\% for montelukast sodium S-enantiomer, $3.2 \%$ for A5 and $3.1 \%$ for A5 R-enantiomer, it indicated that the analytical method has a good repeatability. The test results for intermediate precision displayed that RSDs of 6 results were $3.9 \%$ for montelukast sodium S-enantiomer, $4.0 \%$ for A5 and 3.9\% for A5 R-enantiomer, it indicated that the intermediate precision was good. These test results from repeatability and intermediate precision test manifested that the proposed method in this paper has a good precision.

The test results showed that the LODs were $0.24 \mu \mathrm{g} /$ $\mathrm{ml}$ for montelukast sodium S-enantiomer, $0.13 \mu \mathrm{g} / \mathrm{ml}$ for A5 and $0.11 \mu \mathrm{g} / \mathrm{ml}$ for A5 R-enantiomer, i.e. 2.4 ng, $1.3 \mathrm{ng}$ and $1.1 \mathrm{ng}$, respectively and the LOQs were $0.61 \mu \mathrm{g} / \mathrm{ml}$ for montelukast sodium S-enantiomer, 0.26 $\mu \mathrm{g} / \mathrm{ml}$ for A5 and $0.22 \mu \mathrm{g} / \mathrm{ml}$ for A5 R-enantiomer, i.e. 6.1, 2.6 and $2.2 \mathrm{ng}$, respectively. The LOD was 2.4 ng and the LOQ was $6.1 \mathrm{ng}$ for montelukast sodium S-enantiomer, comparing with the method reported by Radhakrishnan et al. (LOD was $70 \mathrm{ng}$ and LOQ was $200 \mathrm{ng}$ for montelukast sodium S-enantiomer) ${ }^{[24]}$, the LOD was improved approximately 30 times and the LOQ increased by 30 times. The reason accounted for sensitivity increase may be that the mobile phase with dioxane has a more intensive UV background absorption than that of without it that led to a poor light transmittance and reduced the detective sensitivity.

The test results showed that each of the three compounds had a good linearity in the ranges of $0.61 \sim 2.44 \mu \mathrm{g} / \mathrm{ml}$ for montelukast sodium S-enantiomer, 0.26 2.62 $\mu \mathrm{g} /$ $\mathrm{ml}$ for A5 and $0.22 \sim 2.16 \mu \mathrm{g} / \mathrm{ml}$ for A5 R-enantiomer, and the correlation coefficients ( $\mathrm{r}$ ) of the 3 compounds were $0.9978,0.9975$ and 0.9974 , respectively, represented in Table 1. These values indicate that the models are adequate.

The test results for accuracy showed that the recoveries at four levels were ranged from 90.16 to $103.44 \%$ with RSD ranged from 3.39 to $7.45 \%$ for montelukast sodium S-enantiomer and from 95.41 to $108.78 \%$ with RSD from 2.47 to $5.26 \%$ for A5 and from 89.35 to $104.05 \%$ with RSD from 2.84 to $6.22 \%$ for A5 R-enantiomer, 
respectively (Table 2). The results indicate that the method has a good accuracy.

The robustness test results showed that when the chromatographic conditions flow rate, column temperature, columns from different lots and addictive's content were deliberately varied, the resolution between the montelukast sodium and its $\mathrm{S}$ enantiomer was always $>2.4$, and the resolution between A5 and A5 R-enantiomer was $\geq 6.3$. These experiments results showed that the robustness was good under various test conditions (Table 3 ).

The results for stability displayed that the RSDs of six montelukast sodium peak areas during solution stability test was $1.66 \%$, hence, the test sample solution was relatively stable for $12 \mathrm{~h}$, but there is a small impurity peak at the retention time about $13.8 \mathrm{~min}$, the contents were $0.016 \%, 0.022 \%, 0.032 \%, 0.044 \%, 0.052 \%$, $0.06 \%$ for $0 \mathrm{~h}, 1 \mathrm{~h}, 2 \mathrm{~h}, 4 \mathrm{~h}, 8 \mathrm{~h}, 12 \mathrm{~h}$, respectively. It suggested that the sample solution had better complete detection test within $1 \mathrm{~h}$ after sample prepared, while the impurity peak area was increased by $0.044 \%$ from $0 \mathrm{~h}$ to $12 \mathrm{~h}$, it may be disregarded. Three lots of montelukast sodium drug substance were dissolved in hexane:isopropanol:ethanol $(65: 15: 20, \mathrm{v} / \mathrm{v} / \mathrm{v} / \mathrm{v})$ to obtain a solution of $1000 \mu \mathrm{g} / \mathrm{ml}$, separately, and these

TABLE 1: LINEAR EQUATIONS, CORRELATION COEFFICIENTS (R), LOD AND LOQ FOR MONTELUKAST SODIUM S-ENANTIOMER, A5 AND A5 R-ENANTIOMERS

\begin{tabular}{lccccc}
\hline Compound & Linear equation & $\mathrm{r}$ & Linear range $(\mu \mathrm{g} / \mathrm{ml})$ & $\mathrm{LOD}(\mu \mathrm{g} / \mathrm{ml})$ & $\mathrm{LOQ}(\mu \mathrm{g} / \mathrm{ml})$ \\
\hline S-enantiomer & $\mathrm{y}=21.554 \mathrm{x}-2.0932$ & 0.9978 & $0.61 \sim 2.44$ & 0.24 & 0.61 \\
A5 & $\mathrm{y}=29.171 \mathrm{x}-1.7555$ & 0.9975 & $0.26 \sim 2.62$ & 0.13 & 0.26 \\
A5 R-enantiomer & $\mathrm{y}=28.78 \mathrm{x}-1.1473$ & 0.9974 & $0.22 \sim 2.16$ & 0.11 & 0.22 \\
\hline
\end{tabular}

TABLE 2: RECOVERY TEST OF THREE COMPOUNDS

\begin{tabular}{lccccc}
\hline Compound & Spiked limits & Spiked $(\mathbf{n g})$ & Measured \pm SD $(\mathbf{n g})$ & Recovery (\%) & RSD (\%) \\
\hline S-enantiomer & LOQ & 6.1 & $5.50 \pm 0.41$ & 90.16 & 7.45 \\
& $0.08 \%$ & 9.76 & $9.41 \pm 0.32$ & 96.41 & 3.4 \\
& $0.10 \%$ & 12.2 & $12.62 \pm 0.59$ & 103.44 & 4.68 \\
A5 & $0.20 \%$ & 24.4 & $24.16 \pm 0.82$ & 99.02 & 3.39 \\
& LOQ & 2.62 & $2.85 \pm 0.15$ & 108.78 & 5.26 \\
& $0.08 \%$ & 10.46 & $10.12 \pm 0.25$ & 96.75 & 2.47 \\
A5 R-enantiomer & $0.10 \%$ & 13.08 & $12.48 \pm 0.50$ & 95.41 & 4.01 \\
& $0.20 \%$ & 26.16 & $26.73 \pm 0.96$ & 102.18 & 3.59 \\
& LOQ & 2.16 & $1.93 \pm 0.12$ & 89.35 & 6.22 \\
& $0.08 \%$ & 8.64 & $8.99 \pm 0.50$ & 104.05 & 5.56 \\
& $0.10 \%$ & 10.8 & $10.56 \pm 0.30$ & 97.78 & 2.84 \\
\hline
\end{tabular}

TABLE 3: ROBUSTNESS RESULTS OF THE DEVELOPED CHIRAL HPLC METHOD

\begin{tabular}{|c|c|c|}
\hline Parameter & $\begin{array}{l}\text { Resolution between montelukast sodium and } \\
\text { montelukast sodium S-enantiomer }\end{array}$ & $\begin{array}{l}\text { Resolution between A5 and A5 } \\
\text { R-enantiomer }\end{array}$ \\
\hline \multicolumn{3}{|c|}{ Flow rate $(\mathrm{ml} / \mathrm{min})$} \\
\hline 0.8 & 3.13 & 7.14 \\
\hline 0.9 & 2.58 & 6.7 \\
\hline 1 & 2.78 & 6.58 \\
\hline \multicolumn{3}{|c|}{ Column temperature $\left({ }^{\circ}\right)$} \\
\hline 28 & 2.98 & 7 \\
\hline 30 & 2.58 & 6.7 \\
\hline 32 & 2.5 & 6.5 \\
\hline \multicolumn{3}{|c|}{ Column from different lots } \\
\hline ADHӨCE-RC $\Theta 3 \Theta$ & 2.46 & 6.52 \\
\hline ADHӨCE-TG114 & 2.58 & 6.7 \\
\hline ADHӨCE-SG164 & 2.94 & 6.85 \\
\hline \multicolumn{3}{|l|}{ Additives content } \\
\hline $0.09 \%$ TFA and $0.09 \%$ DEA & 2.49 & 6.47 \\
\hline $0.1 \%$ TFA and $0.1 \%$ DEA & 2.58 & 6.7 \\
\hline $0.11 \%$ TFA and $0.11 \%$ DEA & 2.43 & 6.3 \\
\hline
\end{tabular}


samples were tested using the developed method. The results display that all of A5, A5 R-enantiomer and montelukast S-enantiomer were not detected.

A normal-phase chiral HPLC has been established for determination of montelukast sodium S-enantiomer, A5 and A5 R-enantiomer in montelukast sodium bulk drug by studying mobile phase system, chiral columns, flow rates and column temperature. Compared with the methods reported, the proposed method in this paper has a better sensitivity with LOD of $2.4 \mathrm{ng}$ for montelukast S-enantiomer than that reported by Radhakrishnan et $a l .{ }^{[24]}$, the latter was $70 \mathrm{ng}$. Compared with the report by $\mathrm{Liu}^{[22]}$, the proposed method can save test cost due to using a more durable chiral column than that used by Liu, which stationary phase was $\alpha$-acid glycoprotein easily damaged by various organic reagents ${ }^{[23]}$. The development method could meet the requirement for simultaneous determinations of montelukast sodium S-enantiomer, A5 and A5 R-enantiomer in montelukast sodium bulk drug. Furthermore, using the developed HPLC method, A5 and A5 R-enantiomer could reach baseline separation with the resolution more than 6.5. Hence, it also could be used to measure A5 R-enantiomer in A5, contribute to strictly control the content of A5 R-enantiomer in the initial material A5 of montelukast sodium and realize the idea of controlling drug quality from source. In addition, during the process of choosing column, it was found that A5 and its R-enantiomer were well separated on Daicel Chiracel ${ }^{\circledR} \mathrm{OJ}-\mathrm{H}$ chiral column with resolution of 5.2 using the developed method and the peak order of two enantiomers was reversed compared with that performed on Daicel Chiralpak ${ }^{\circledR}$ AD-H chiral column, for this result, the reason may be that each kind of chiral column packing has specific selectivity for different chiral compounds.

\section{Acknowledgements:}

The authors thank Disha Pharmaceutical Group for giving the support to complete the study and acknowledge their colleagues for their cooperation in carrying out this work. The authors have declared no conflict of interest.

\section{Conflict of interest:}

The authors declare no conflicts of interest.

\section{Financial support and sponsorship:}

Nil.

\section{REFERENCES}

1. Samuelsson B, Borgeat P, Hammarström S, Murphy RC. Introduction of a nomenclature: leukotrienes. Prostaglandins 1979;17:785-87.

2. Rouzer CA, Shimizu T, Samuelsson B. On the nature of the 5-lipoxygenase reaction in human leukocytes: Characterization of a membrane-associated stimulatory factor. Proc Natl Acad Sci USA 1985;82:7505-9.

3. Holgate ST, Peters-Golden M, Panettieri RA, Henderson WR. Roles of cysteinyl leukotrienes in airway inflammation, smooth muscle function, and remodeling. J Allergy Clin Immunol 2003;111:S18-34.

4. Samuelsson B. Leukotrienes: Mediators of immediate hypersensitivity reactions and inflammation. Science 1983;220;568-75.

5. Capra V, Thompson MD, Sala A, Cole DE, Folco G, Rovati GE. Cysteinyl-leukotrienes and their receptors in asthma and other infammatory diseases: critical update and emerging trends. Med Res Rev 2007;27:469-527.

6. Rupprecht T, Rupprecht C, Harms D, Sterlacci W, Vieth M, Seybold K. Leukotriene receptor blockade as a life-saving treatment in severe bronchopulmonary dysplasia. Respiration 2014;88:285-90.

7. Labelle M, Belley M, Gareau Y, Gauthier JY, Guay D, Gordon $\mathrm{R}$, et al. Discovery of MK-0467, a potent and orally active leukotriene D4 receptor antagonist devoid of peroxisomal enzyme induction. Bioorg Med Chem Lett 1995;5:283-8.

8. Reiss TF, Altman LC, Chervinsky P, Bewtra A, Stricker WE, Noonan GP, et al. Effects of montelukast (MK-0476), a new potent cysteinyl leukotriene (LTD4) receptor antagonist, in patients with chronic asthma. J Allergy Clin Immunol 1996;98:528-34.

9. Steib CJ, Bilzer M, Winkel M, Pfeiler S, Hartmann AC, Hennenberg $\mathrm{M}$, et al. Treatment with the leukotriene inhibitor montelukast for 10 days attenuates portal hypertension in rat liver cirrhosis. Hepatology 2010;51:2086-96.

10. Carver TW Jr. Exercise-induced asthma: critical analysis of the protective role of montelukast. J Asthma Allergy 2009;2:93-103.

11. Lee DKC, Haggart K, Robb FM, Lipworth BJ. Montelukast protects against nasal lysine-aspirin challenge in patients with aspirin-induced asthma. Eur Respir J 2004;24:226-30.

12. Yilmaz O, Altintas D, Rondon C, Cingi C, Oghan F. Effectiveness of montelukast in pediatric patients with allergic rhinitis. Int J Pediatr Otorhinolaryngol 2013;77:1922-4.

13. Ge $\mathrm{S}$, Zhou $\mathrm{G}$, Cheng $\mathrm{S}$, Liu $\mathrm{D}, \mathrm{Xu} \mathrm{J}, \mathrm{Xu} \mathrm{G}$, et al. Antiatherogenic effects of montelukast associated with reduced MCP-1 expression in a rabbit carotid balloon injury model. Atherosclerosis 2009;20:574-9.

14. Warner JO. The role of leukotriene receptor antagonists in the treatment of chronic asthma in childhood. Allergy 2001;56:22-9.

15. Lommatzsch M, Virchow JC. Severe asthma: definition, diagnosis and treatment. Dtsch Arztebl Int 2014;111:847-55.

16. Cavalluzzi MM, Viale M, Bruno C, Carocci A, Catalano A, Carrieri A, et al. A convenient synthesis of lubeluzole and its enantiomer: Evaluation as chemosensitizing agents on human ovarian adenocarcinoma and lung carcinoma cells. Bioorg Med Chem Lett 2013;23:4820-3.

17. Jacques V, Czarnika AW, Judgeb TM, Ploega LHTV, DeWitt SH. Differentiation of antiinflammatory and antitumorigenic properties of stabilized enantiomers of thalidomide analogs. Proc Natl Acad Sci USA 2015; March 9: E1471-9.

18. https://www.ich.org/fileadmin/Public_Web_Site/ICH Products/Guidelines/Quality/Q3A_R2/Step4/Q3A_R2_ Guideline.pdf. 


\section{www.ijpsonline.com}

19. Saravanan M, Kumari KS, Reddy PP, Naidu MN, Babu JM, Srivastava AK, et al. Identification, synthesis, isolation and spectral characterization of potential impurities of montelukast sodium. J Pharm Biomed Anal 2008;48:708-15.

20. Bollikonda S, Mohanarangam S, Jinna RR, Kandirelli VKK, Makthala L, Sen S, et al. An enantioselective formal synthesis of montelukast sodium. J Org Chem 2015;80:3891-901.

21. Redondo J, Capdevila A, Ciudad S. Determination of the enantiomeric purity of the antiasthmatic drug montelukast by means of ${ }^{1} \mathrm{H}$ NMR spectroscopy. Chirality 2013;25:780-6.

22. Liu L, Cheng H, Zhao JJ, Rogers JD. Determination of montelukast (MK-0476) and its S-enantiomer in human plasma by stereo selective high-performance liquid chromatography with column-switching. J Pharm Biomed Anal 1997;15:631-8.

23. Wainer IW, Jadaud P, Schombaum GR, Kadodkar SV, Henry MP. Enzymes as HPLC stationary phases for chiral resolutions: Initial investigations with $\alpha$-chymotrypsin. Chromatographia 1988;25:903-7.

24. Radhakrishnan P, Rao DVS, Surendranath KV, Subrahmanyam D, Himabindu V. A validated LC method for determination of the enantiomeric purity of montelukast sodium in bulk drug samples and pharmaceutical dosage forms. Chromatographia 2008;68:263-7. 